\title{
Aneurysmal bone cyst: a rare surgical tumor of the rib
}

\author{
Marius Kamdem ${ }^{1}$, Massine el Hammoumi ${ }^{1}$, Mouad Amraoui ${ }^{1}$, Mohamed Bhairis ${ }^{1}$, Mohamed Oukabli ${ }^{2}$, \\ el Hassane Kabiri ${ }^{1}$
}

${ }^{1}$ Department of Thoracic Surgery, Mohammed V Military Teaching Hospital, Rabat, Morocco

2Department of Pathology, Mohammed V Military Teaching Hospital, Rabat, Morocco

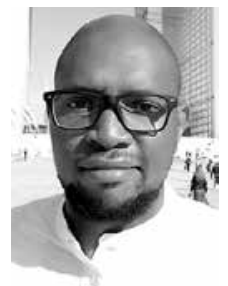

Kardiochirurgia i Torakochirurgia Polska 2021; 18 (4): 268-271

Bone cyst is a benign osteolytic cyst that develops within bone. There are mainly two types of bone cysts: the common form, simple bone cyst; and aneurysmal bone cyst $(A B C)$, the uncommon form. The latter is rare and affects about one in a million people in a given year [1]. The most common location is on the long bone of legs, upper arms, spine, and pelvis [1]. The rib is an uncommon location of $A B C$. We report here two cases of $A B C$ of the ribs.

Case 1: A 59-year-old male patient was admitted in March 2018 with a complaint of an increasing swelling of the left base of chest wall since 1 year before. There was no fever or respiratory associated symptoms. On physical examination, the left anterior chest wall in the $8^{\text {th }}$ rib was slightly bulging, with no mass palpation. Plain and lateral chest radiographs revealed a chest shadow (Figure $1 \mathrm{~A}$ ). Computed tomography (CT) scan of the chest revealed a regular-shaped $66 \times 47 \times 48 \mathrm{~mm}$ bone cyst in the anterior $8^{\text {th }}$ rib (Figure $1 \mathrm{~B}$ ). Magnetic resonance imaging (MRI) and ultrasound were performed and confirmed the diagnosis of bone cyst but with a suspicion of the hydatid origin of the cyst, while laboratory assessments were all within normal limits. Complete removal surgery was performed through a left posterolateral thoracotomy (Figure 2). An anatomo-

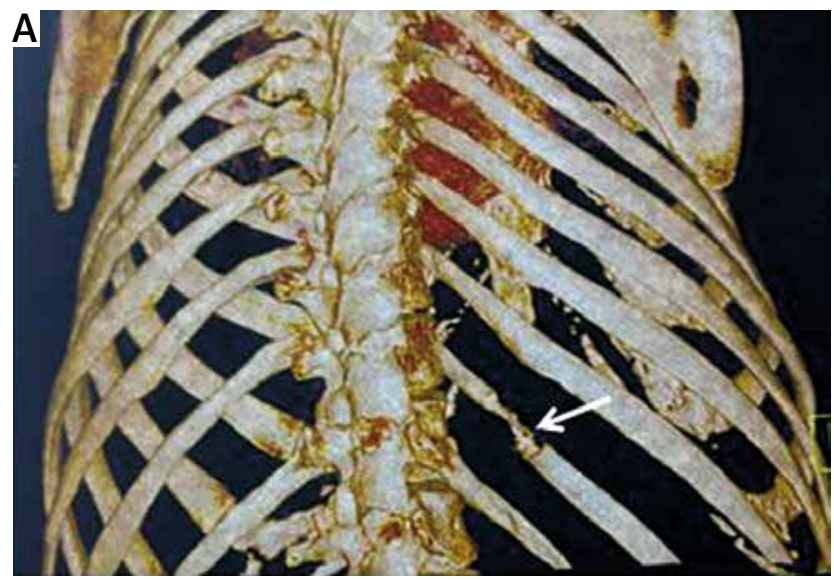

Figure 1. Chest CT (A) and MRI (B) of an aneurysmal cyst of the rib pathologist confirmed the diagnosis of $A B C$ with a free surgical margin. Five year follow-up revealed no recurrence.

Case 2: A 57-year-old female patient presented in September 2015 with a 2-year history of right posterior chest swelling with pain. On physical examination, the right posterior chest wall in the region of the $9^{\text {th }}$ rib was bulging. The respiratory sounds were normal. Chest X-rays (Figure $3 \mathrm{~A}$ ) and computed tomography (CT) scan showed a posterior irregular shaped bone cyst of the $9^{\text {th }}$ rib. Laboratory data were all within normal values. A right sided posterolateral thoracotomy was performed with complete removal (Figure 4). A microscopic examination showed a blood-filled space, surrounded by a fibrous wall; granulation and giant cells were found in the cyst wall (Figures $5 \mathrm{~A}, \mathrm{~B}$ ). The surgical margin was free and no malignant lesion was observed. Follow-up during 3 years was uneventful.

$A B C$ located in the rib is particularly rare, about $2.7 \%$ of all $A B C[1,2]$. It may occur in every rib [2]. About $29 \%$ of reported cases have been found incidentally by a routine chest X-ray but it is usually associated with pain, swelling, a palpable lump, dyspnea, paraplegia, or pathological fractures [1]. The etiology of $A B C$ is unknown but arteriovenous malformation is a widely accepted theory. The radiological

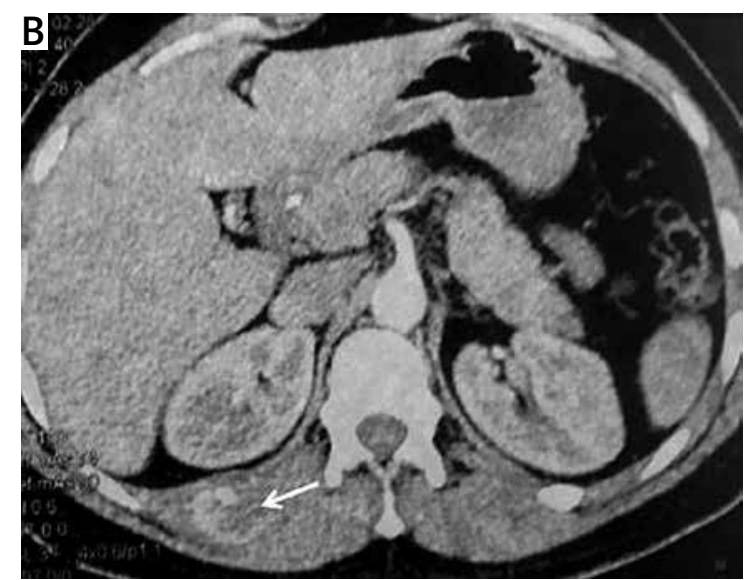

Address for correspondence: Prof. Massine el Hammoumi, Department of Thoracic Surgery, Mohammed V Military Teaching Hospital, Rabat, Morocco, e-mail: hamoumimassine@hotmail.fr

Received: 12.07.2021, accepted: 26.09.2021. 

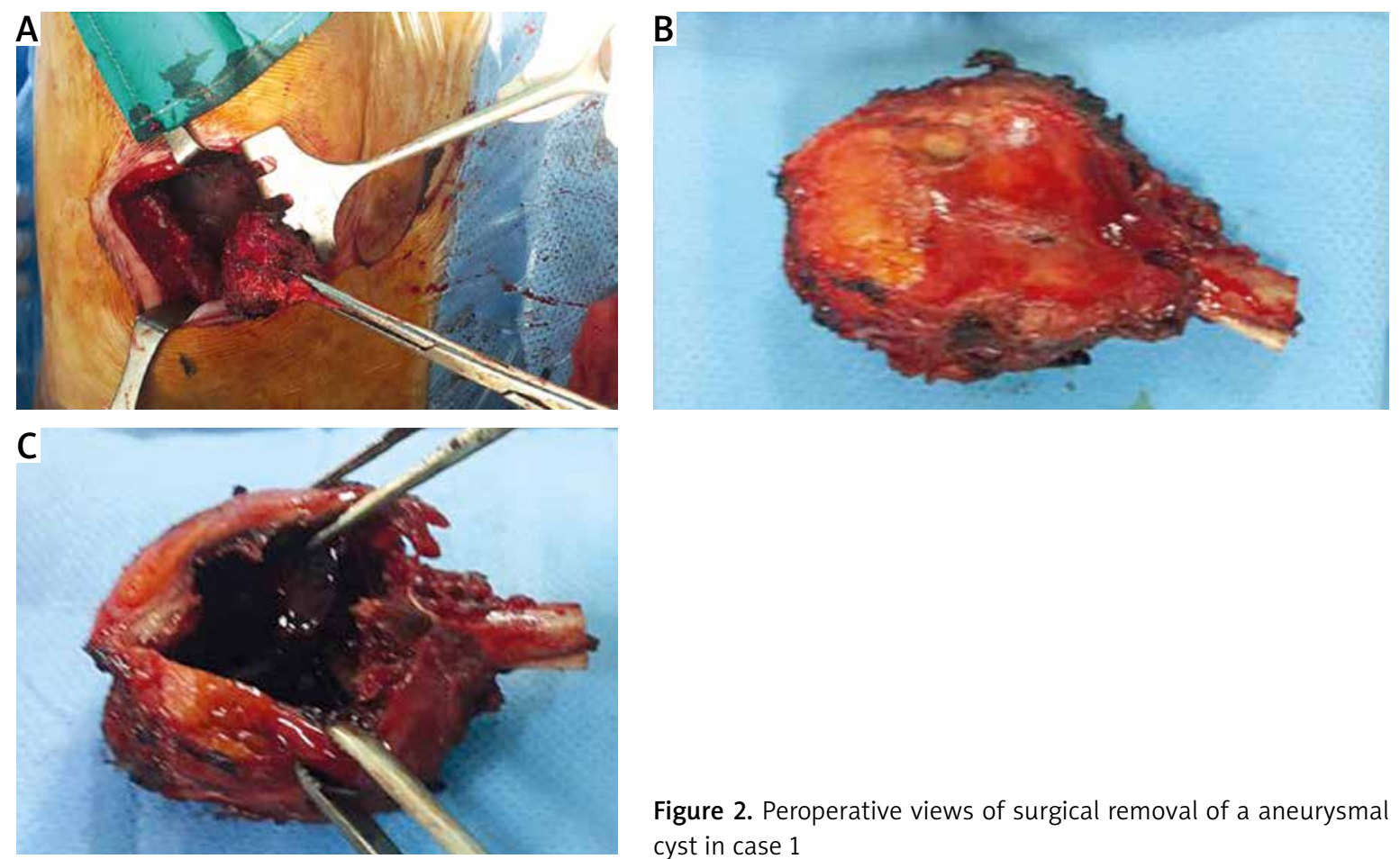

Figure 2. Peroperative views of surgical removal of a aneurysmal cyst in case 1
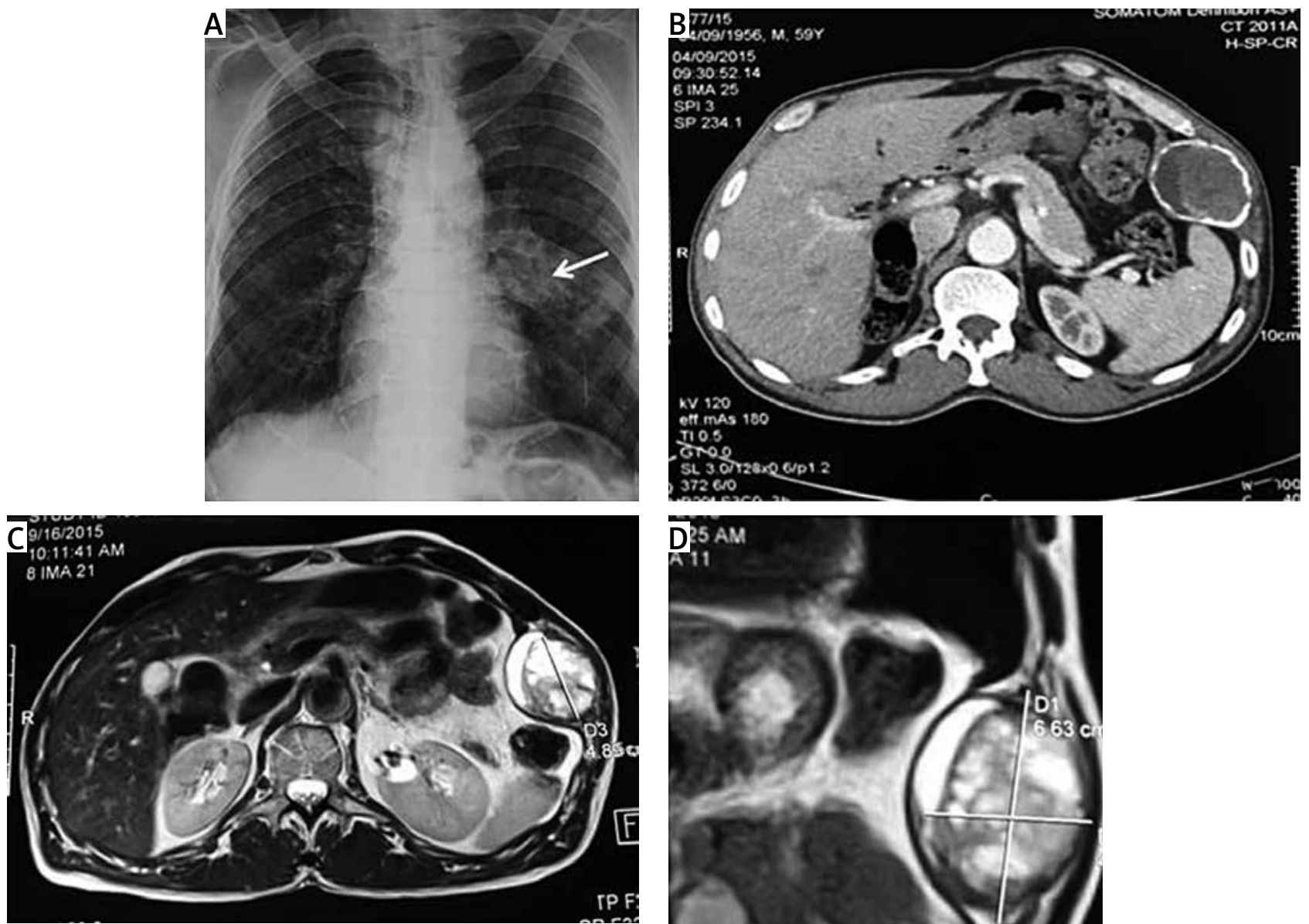

Figure 3. Radiological findings in case 2. A - Chest radiograph showing left paracardiac shadow. B - CT scan revealing an osteolytic lesion of the anterior bow of the $8^{\text {th }}$ rib. C, D - MRI exposed the expandable character of the osteolytic lesion with multiloculated blood-filled cavities with a "honeycomb" appearance

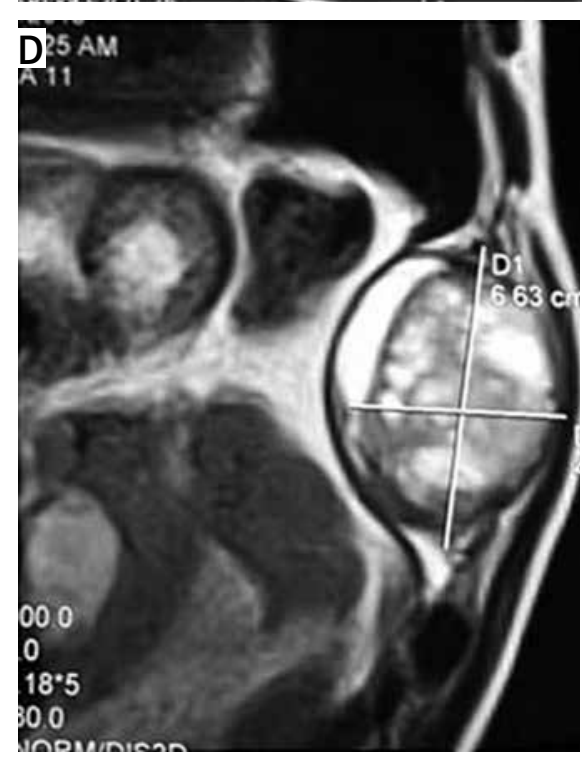



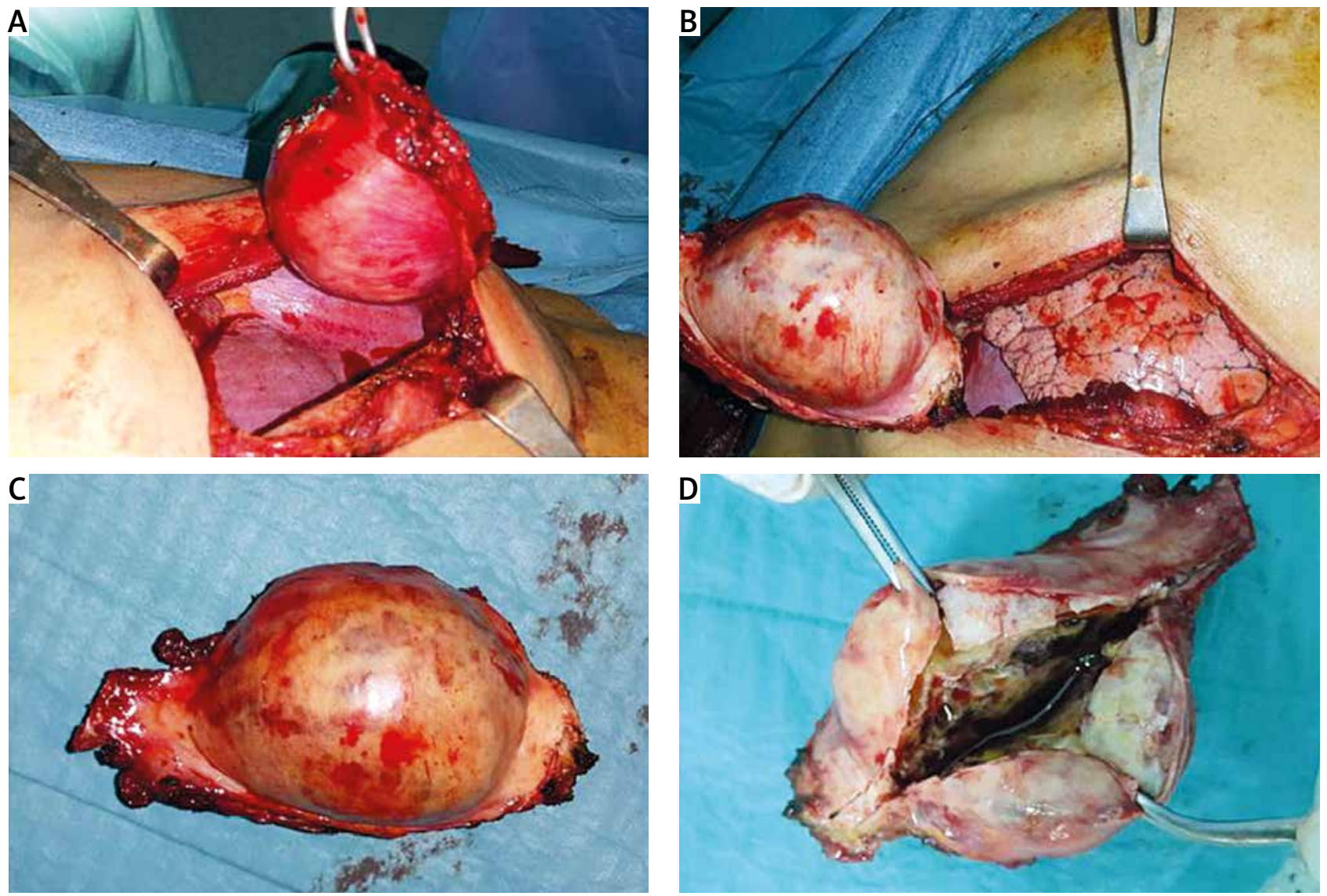

Figure 4. Surgical bloc resection of the rib cyst by posterolateral thoracotomy
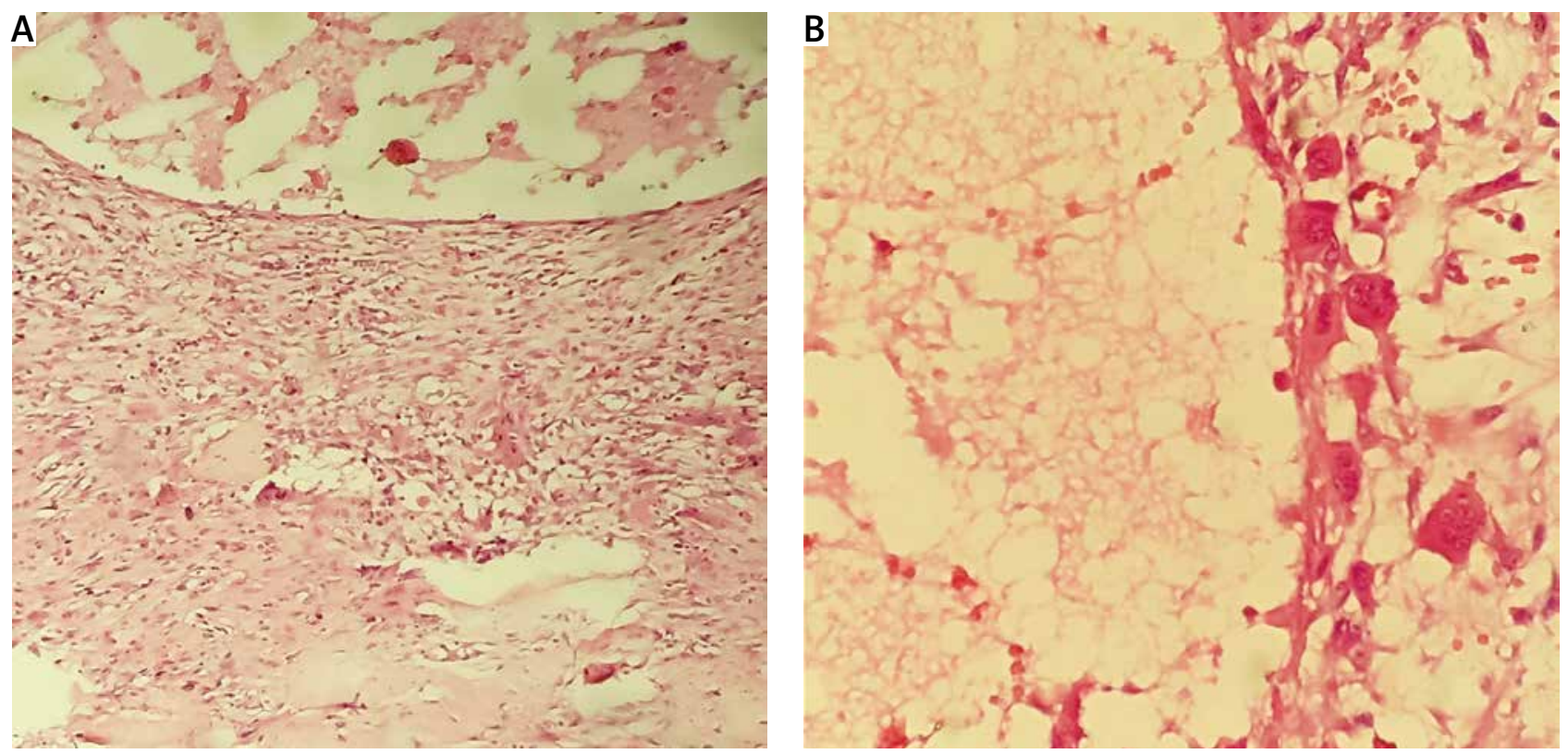

Figure 5. Cystic feature with hemorrhagic content in fibrous tissue containing some osteoclast active cells in a dystrophic bone tissue $(A-H+E, 40 \times, B-H+E, 100 \times)$

data of costal $A B C$ are not sufficiently specific to establish a definitive diagnosis; CT scan or MRI has great value to demonstrate the characteristic findings of the condition, namely an expansile lytic bony lesion with multiloculated blood-filled cavities with a 'soap bubble' or 'honeycomb' appearance [3]. However, it is often difficult to obtain a precise preoperative diagnosis. The usual differential diagnosis in young children is between an $A B C$ and simple bone cyst, and in young adults between $A B C$ and giant cell tumor. In pathology $A B C$ has a uniform pattern: large cystic spaces 
filled with blood and separated by fibrous septa, alternating with solid areas. Primary lesions arise with no known cause. Secondary ABCs arise from another preceding lesion, and these are presumed to occur as the result of an intralesional hemorrhage within the primary lesion. Primary $A B C$ s such as in our cases are uncommon; they represent only $5-7 \%$ of all bone tumors $[1,4]$. Approximately onethird are the secondary type [5]. Therefore surgical treatment is recommended, but other methods of treatment are available such as curopsy, embolization, cryotherapy, sclerotherapy or radiotherapy. Local extension can cause pathologic fractures, paralysis due to spinal cord compression, compression of the vital organs and malignant transformation. To date, complete surgery and large excision allow the lowest risk of local recurrence [2]. However, few authors have reported recurrence after a total excision $[6,7]$. Radiotherapy should be considered only for inoperable cases, keeping in mind that transformation into a sarcoma due to irradiation is possible $[3,8]$.

In conclusion, $\mathrm{ABC}$ of the rib is a rare, benign condition which is considered in the differential diagnosis of chest wall tumors. Surgery by bloc resection of the mass and af- fected portion of the rib can be curative and provide good results due to potential risk of recurrence.

\section{Disclosure}

The authors report no conflict of interest.

\section{References}

1. Yasaroglu M, Ketenci B, Demirbag H, Yildirim M, Dogusoy I. Aneurysmal bone cyst of the rib: a case report. J Med Case Reports 2009; 3: 8457.

2. Kumar V, Singh RS, Rawat S, Gupta K, Parikh M. A large aneurysmal bone cyst of the rib. Asian Cardiovasc Thorac Ann 2019; 27: 313-315.

3. Hughes EK, James SL, Butt S, Davies AM, Saifuddin A. Benign primary tumours of the ribs. Clin Radiol 2006; 61: 314-322.

4. Moraitis S, Moraitis D, Chounti M, Hountis P. Aneurysmal rib cyst. Monaldi Arch Chest Dis 2017; 87: 860 .

5. Guo J, Liang C. A giant aneurysmal bone cyst of the rib: case report. Oncol Lett 2014; 7: 267-269.

6. Ruiter DJ, van Rijssel TG, van der Velde EA. Aneurysmal bone cysts: a clinicopathological study of 105 cases. Cancer 1977; 39: 2231-2239.

7. Tillman BP, Dahlin DC, Lipscomb PR, Lipscomb PR, Stewart JR. Aneurysmal bone cyst: an analysis of ninety-five cases. Mayo Clin Proc 1968; 43: 478-495.

8. Yoshida K. Aneurysmal bone cyst of the rib: report of a case. Surg Today 2005; 35: 1073-1075. 